\title{
Development and Validation of Robot Patient Equipped with an Inertial Measurement Unit and Angular Position Sensors to Evaluate Transfer Skills of Nurses
}

\author{
Chingszu Lin ${ }^{1}(1) \cdot$ Taiki Ogata $^{2} \cdot$ Zhihang Zhong $^{3} \cdot$ Masako Kanai-Pak $^{4} \cdot$ Jukai Maeda $^{5} \cdot$ Yasuko Kitajima $^{6}$. \\ Mitsuhiro Nakamura ${ }^{7} \cdot$ Noriaki Kuwahara $^{8} \cdot$ Jun Ota $^{9}$
}

Accepted: 25 June 2020 / Published online: 23 July 2020

(c) The Author(s) 2020

\begin{abstract}
To more efficiently enhance the patient transfer skills of nursing students, this study aims to integrate a transfer skills evaluation system and a robot patient. The evaluation parameters, namely, the translational acceleration of the waist, rotational speed of the chest, and joint angles of the shoulder, hip, and knee, were selected on the basis of the pre-experimental results obtained with a simulated patient acted by the human individuals. To measure these parameters, inertial measurement unit (IMU) and angular position sensors were installed on the robot patient. An experiment was conducted with four nursing teachers to verify whether the robot patient could distinguish the incorrect methods of the transfer skills, determined to be a common mistake made by the nurses. According to the results, most transfer steps had the same effect on the simulated patient and the robot patient, which demonstrates that the robot patient is a suitable substitute for an actual patient. However, in certain steps, the robot patient was not able to distinguish between the correct and incorrect methods using the chosen parameters owing to the differences being insignificant. These insignificant differences were mostly attributed to the passive joint design of the robot patient.
\end{abstract}

Keywords Robot patient $\cdot$ Nursing education $\cdot$ Human patient simulator $\cdot$ Patient transfer skill

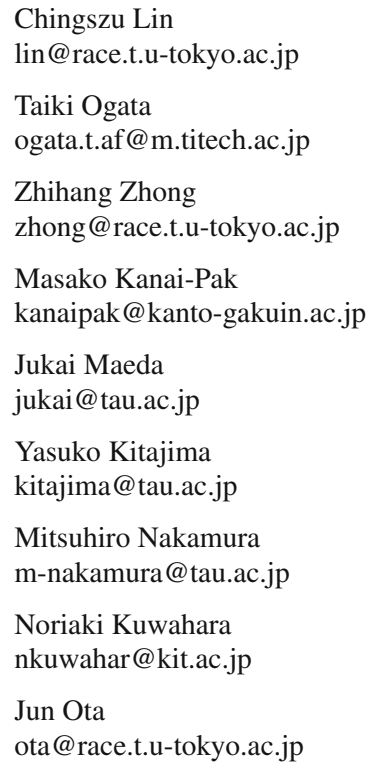

Department of Precision Engineering, Graduate School of Engineering, The University of Tokyo, Tokyo 113-8656, Japan

2 School of Computing, Tokyo Institute of Technology, Tokyo 152-8550, Japan

3 Department of Precision Engineering, Graduate School of Engineering, The University of Tokyo, Tokyo 113-8656, Japan

4 Faculty of Nursing, Kanto Gakuin University, Yokohama 236-8501, Japan

5 Faculty of Nursing, Tokyo Ariake University of Medical and Health Sciences, Tokyo 135-0063, Japan

6 Faculty of Nursing, Tokyo Ariake University of Medical and Health Sciences, Tokyo 135-0063, Japan

7 Faculty of Nursing, Tokyo Ariake University of Medical and Health Sciences, Tokyo 135-0063, Japan

8 Department of Advanced Fibro-Science, Kyoto Institute of Technology, Kyoto 606-8585, Japan 


\section{Introduction}

According to demographic statistics, the number of elderly people worldwide has recently surpassed 700 million [1]. As this population is at a high risk of suffering from agingassociated diseases [2], there is an increasing demand for nursing healthcare at hospitals and care centers. However, the current supply of qualified nursing candidates does not meet these requirements [3]. Potential causes of this shortage may stem from the current situation at nursing schools. Several previous studies claim that high student-faculty ratios and large class sizes at nursing schools are possible barriers to learning [4,5]. As it is difficult for teachers to supervise each student and provide individualized feedback, students are unable to improve their skills [6,7]. Moreover, students only have few opportunities to practice with actual patients, which limits their opportunities to obtain practical experience [8]. As a result, new nursing school graduates may require several years to become experts after launching their careers at hospitals [9]. Therefore, human patient simulators (HPSs) and evaluation systems to assess student skills are becoming crucial in nursing education.

Various evaluation systems have been proposed to assess the skills of trainees. For example, in the field of sports, a system was implemented to analyze swimming skills [10]. An evaluation system using inertial sensors was proposed for golf training by [11]. Gray et al. and Furuya and Kinoshita $[12,13]$ observed the differences between the arm movements of novice and expert baseball players and pianists. An approach to evaluate musical performance was also introduced into a robotic system in [14]. In the nursing field, an RGB-D camera-based learning system for a bedmaking activity was proposed by [15]. A method to assess trainee behavior related to clinical teamwork was introduced in [16]. Additionally, in a previous study, we proposed a transfer skills evaluation system that uses a Kinect camera and color markers attached to patients and students [17]. Evaluation systems for nursing skills require that a patient receive care from a nursing trainee during the evaluation. As previously mentioned, there is an insufficient number of faculty to portray the patients. Therefore, HPSs should be considered as a means to improve the education at nursing schools.

Unlike simulated patients (SPs) portrayed by experienced individuals (e.g., therapists and experienced nurses), an HPS is a simulator that emulates a living patient. The first HPS, i.e., a mannequin, was introduced in the 1950 s to teach physical assessments to nursing students [18]. Since then, HSPs have been widely developed and implemented for different training tasks. For example, upper and lower limb robots

9 Research into Artifacts Center for Engineering (RACE), School of Engineering, The University of Tokyo, Tokyo 113-8656, Japan
$[19,20]$ were developed to train physical therapists, as well as a robotic hand designed for rehabilitation purposes [21]. Computerized simulators have been employed in trauma management training [22], dentist training [23], and epidural injection [24]. A patient mannequin was developed to train nurses in changing patient clothing [25]. Others have been developed for medical diagnosis training for prostate and cardiac examinations $[26,27]$. Other studies have introduced simulators that simulate the airway $[28,29]$ and swallowing difficulties [30] to facilitate clinical assessments and rehabilitation activities. Additionally, in previous studies [31,32], we developed and employed a robot patient for transfer training; also [33] verified that trainees who practiced with the proposed robot patient revealed a significant improvement in most skills of transfer task, which is similar to the results of nurse teachers practicing with SPs. However, most developed HPSs do not consider evaluation systems. Thus, the teachers must still accompany the student to assess their performance during practice.

This study focuses on the transfer skill as one of the patient handling skills because of the difficulties involved in employing the proper body mechanics and its indispensability to the patient's daily life. In addition, with a rapidly increasing aging population in Japan [34], we first target elderly patients affected by weakness in their lower limbs, and who require transfer assistance. After the validation, the range of applications could be extended to other types of patients. Although previous studies have separately developed evaluation systems and robot patients for transfer training, as shown in Fig. 1a, this study aims to integrate them. An HPS, or robot patient, is indispensable during training because it provides nursing students a subject on which to practice. Also the HPS is usually equipped with sensors to measure movement to convey the condition of the patient. Meanwhile, one of our early studies [35] demonstrated that nursing skills can be indirectly evaluated using only patient movements. Therefore, we intend to use movements measured by sensors on a robot patient to assess nursing skills, as shown in Fig. 1b. As a result, the problem described in [17], where camera calibration sensor installation on trainees requires a significant amount of time (i.e., color markers), can be solved as well.

Developing a robot patient capable of using movement sensors to evaluate the transfer skills of nursing students is challenging due to the wide array of data that can be measured. Limiting the number of sensors installed on the robot is preferable because this simplifies hardware development. Therefore, we analyzed the results of a previous study conducted with an SP [35], by examining the level of significant differences, to narrow the data to the parameters: the translational acceleration of the waist, rotational speed of the chest, and joint angles of the shoulder, hip, and knee. Further, we improved the robot patient reported in [32] by installing an inertial measurement unit (IMU) and angular 


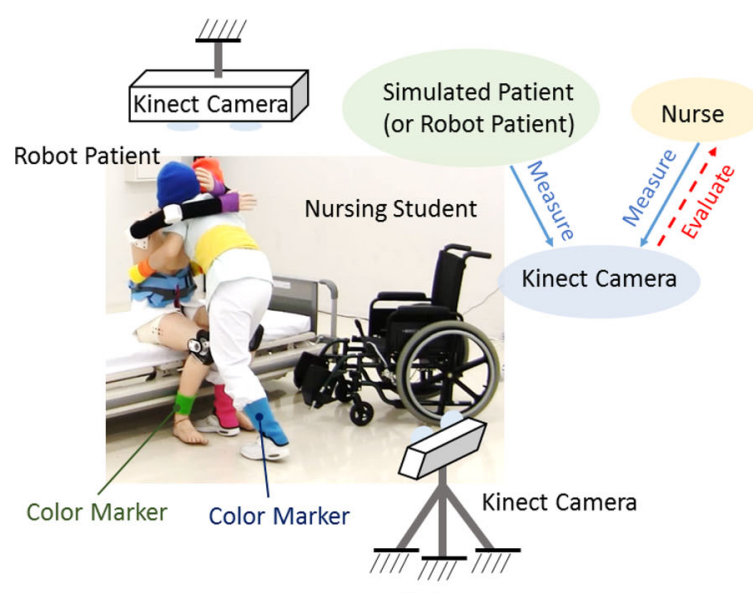

(a)

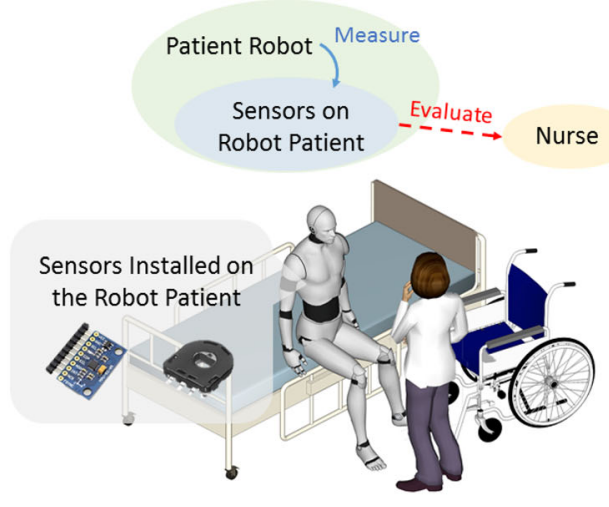

(b)

Fig. 1 The evaluation system and robot patient for transfer skill learning from (a) previous study and b the integration of this study

position sensors to measure those parameters. An experiment was conducted with nursing teachers $(n=4)$ instructed to perform correct and incorrect methods of patient transfer. Results show that the parameter values measured by the robot patient indicate significant differences in nine of the thirteen incorrect methods of the transfer skill in terms of the effects on the robot patient. Moreover, a comparison with [35] showed that, during most steps, the effects on the robot patient were identical to the effects on the SPs portrayed by nursing teachers.

The main contribution of this study is to introduce the assessment method we proposed in our preliminary work [35] on a robot patient. To achieve this, the number of parameters that were measured was first reduced by avoiding the installation of redundant sensors on the robot. Integration of the robot patient with the assessment method was verified by conducting an experiment with nursing teachers. In addition, the difference between the robot patient and SPs were analyzed, after which the developed robot patient was determined to be suitable for use in future applications in clinical training to enhance nurses' skills. Furthermore, the results are beneficial for education purpose especially with respect to low actual patient accessibility.

The remainder of the study is structured as follows. Section 2 introduces the patient transfer process. Section 3 presents the methodology, and Sect. 4 describes robot patient development. Section 5 describes the experiment and subsequently outlines the results. Section 6 discusses and interprets the results in detail. Section 7 concludes this study and comments on future research that can expand the knowledge gained in this study.

\section{Patient Transfer Skill}

During a patient transfer, a patient is moved from a bed to a wheelchair, or vice-versa. This skill is indispensable in the care of hospital patients who must use the restroom. However, such transfers are considered difficult [36] due to the involvement of patient-nurse interactions and full body mechanics. Appropriate body mechanics allow the strength of the patient to be used during the transfer, which prevents injury to the nurses. For example, when repeatedly lifting patients to assist them in standing, inappropriate body mechanics may cause lower back pain in nurses [37]. Employing correct body mechanics increases the safety and comfort of patients [38]. However, such body mechanics are difficult to learn without opportunities to practice with patients. Therefore, we selected patient transfers as the skill that requires enhancement.

According to nursing materials, an appropriate transfer method differs depending on a patient's conditions, such symptoms and disability. In this study, we first focused on a specific elderly patient who experienced weak muscle strength and functional independence in the lower limbs. Patients in situations such as these are in need of transfer assistance.

\subsection{Procedure}

In this study, the transfer process begins with the patient sitting on the bed. It involves transferring the patient from the bed to a wheelchair. Figure 2 presents the transfer procedure. The main steps include placing the wheelchair, moving the patient to the edge of the bed, mutual hugging, assisting the patient to stand, pivot turning, placing the patient in the wheelchair, and final posture adjustment. 


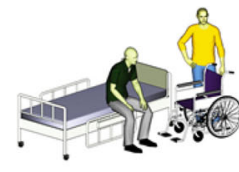

No. 1 - 3

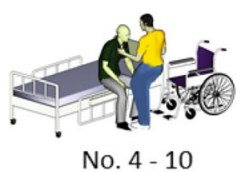

No. 4 - 10

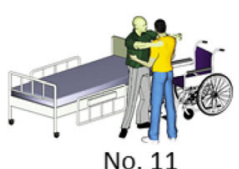

No. 11

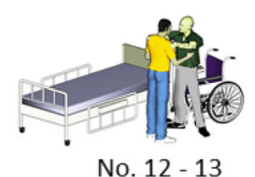

No. $12-13$
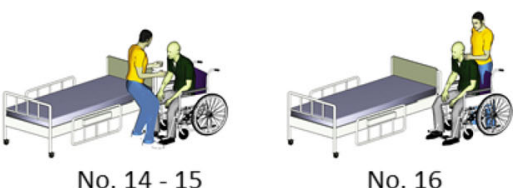

Fig. 2 A diagram of the patient transfer procedure

\subsection{Checklist for Patient Transfer Skill}

To evaluate the transfer skill, Lin et al. [35] proposed a checklist to transfer a patient suffering from weak lower limbs. The checklist includes both correct and incorrect methods, which were determined based on discussions with nursing teachers and reviews of nursing materials, as presented in Fig. 3 and Table 1. There are a total of 16 steps in a transfer when performed with the correct methods, whereas there are 12 steps in a transfer comprised of 13 incorrect methods. The incorrect methods represent common mistakes made by nurses based on the clinical experience of nursing teachers. However, both the correct and incorrect methods presented in Table 1 are only limited to patients who are affected by weakness of the lower limb. This is because other types of patients would have to be handled in different ways, and the corresponding common mistakes would also differ.

\section{Methodology}

An HPS typically contains a number of sensors that measure data, which is crucial information that represents the condition of a patient. For example, Noh et al. [28] measured the pressure and force from the simulator to indicate airway conditions. However, most previous studies have not investigated the relationship between the measurements from the patient and the skill of the nurses or therapists. To address this issue, Lin et al. [35] examined the relationship between patient movements and nursing skill. The results revealed that patient measurements can be used to evaluate nursing skills. Accordingly, this study aims to use the sensing function of an HSP to assess the transfer skills of the nurses. The robot patient can emulate the patient and evaluate the skills of the nurses without a need for sensors in the environment or on the trainees. Such integration of a robot and evaluation system also allows us to solve problems encountered in our earlier studies [17], in which applicability was reduced due to the need to calibrate cameras and install sensors on trainees. Specifically, if the training location is changed, the camera must be re-calibrated, where a large number of trainees requires a time-consuming sensor installation process.

\subsection{Indirect evaluation of the transfer skill method}

This study employed the indirect evaluation method described in [35], in which only the patient is measured during the transfer skill evaluation. Employing the indirect evaluation method allows us to avoid the use of sensors and cameras to measure nurse movements. Under such a method, patient movement becomes independent for assessments. This indirect method can assess the nursing skill due to mutual and physical iterations between the patient and nurse. Therefore, such indirect evaluation approach it is necessary for the nursing students who are capable of executing the transfer correctly or incorrectly to contribute to the patient movement. According to the results of an experiment conducted with an SP, the skill of the nurse has a significant effect on patient movement. And the effects of the following incorrect transfer methods differ from those observed when following the correct transfer methods, as listed in Table 1. For example, in step No. 14, if a nurse does not lower the waist while helping the patient sit in a wheelchair, the patient would sit down more rapidly with an increased translational acceleration.

\subsection{Evaluation Parameter Determination}

In our previous study [35], we measured thirty parameters by using the simulated patient, as presented in Table 2. However, some of the data was redundant in terms of the evaluation of the correctness of the nursing skills. This was because some of the data did not indicate the different effects of following the correct or incorrect methods, and the correctness of a skill in a certain step can be inferred from more than one measured data. Moreover, it is preferable to minimize the number of measured parameters in order to simplify the mechanical development of the robot. Therefore, to more effectively evaluate the transfer skill, we used a smaller number of parameters to reduce and determine the evaluation parameters. To reduce the number of parameters, a statistical analysis in the form of the t-test was conducted to examine the level at which the difference is significant, and the independent variable was set as the correctness of the skill (correct/incorrect). In each step, the parameter which is the most different under the incorrect method was determined. Accordingly, the thirty parameters were reduced to eight parameters, as presented 

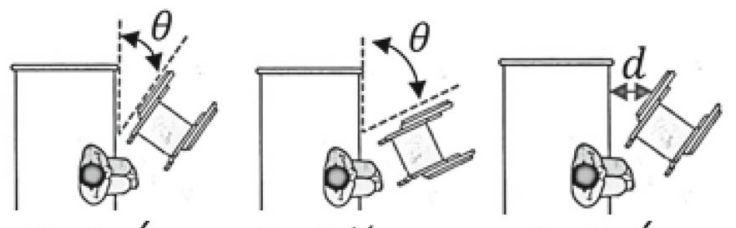

No.1 $X$

No.2 $\sqrt{ }$
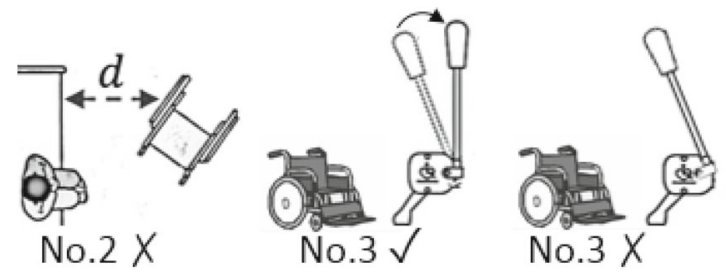

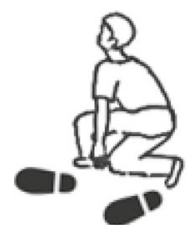

No.4 $\sqrt{ }$

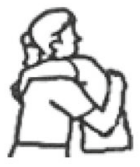

No.7 $\sqrt{ }$

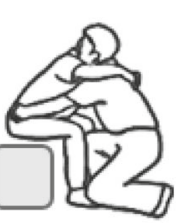

No.10 $\sqrt{ }$

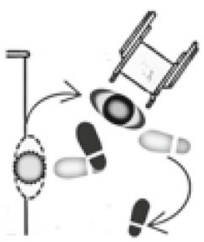

No.12 $\sqrt{ }$
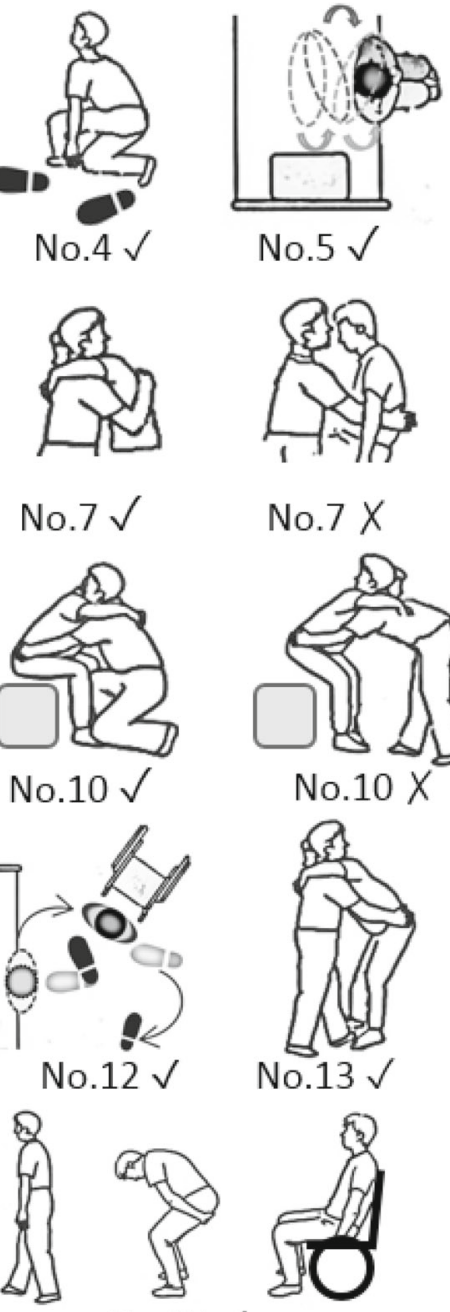

No.5 $\sqrt{ }$

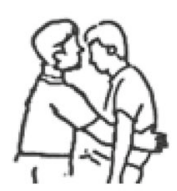

No.7 $X$

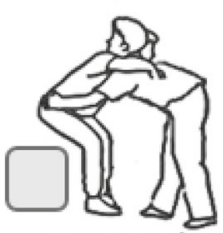

No. $10 X$

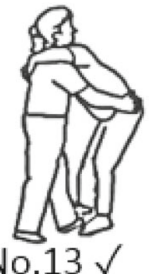

No.13 $\checkmark$

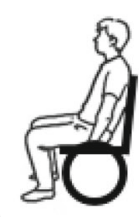

No.15 $\sqrt{ }$

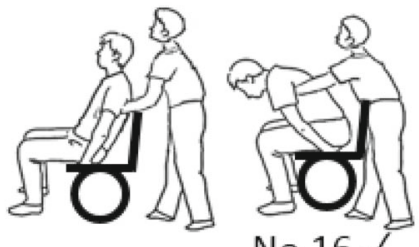

No.16 $\sqrt{ }$

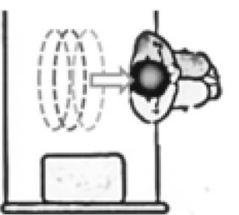

No. 5 X-(1)

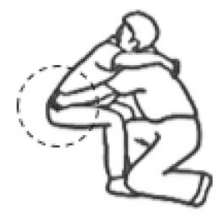

No.8 $\sqrt{ }$
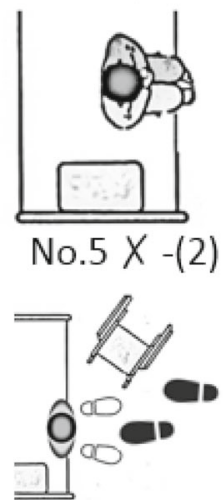

No.9 $\checkmark$

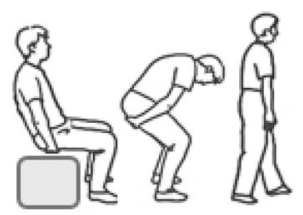

No.11 $\sqrt{ }$

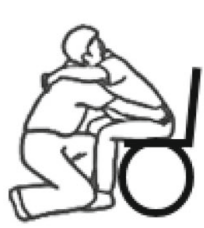

No.14 $\checkmark$

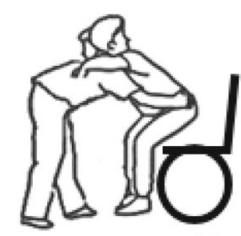

No.14 X
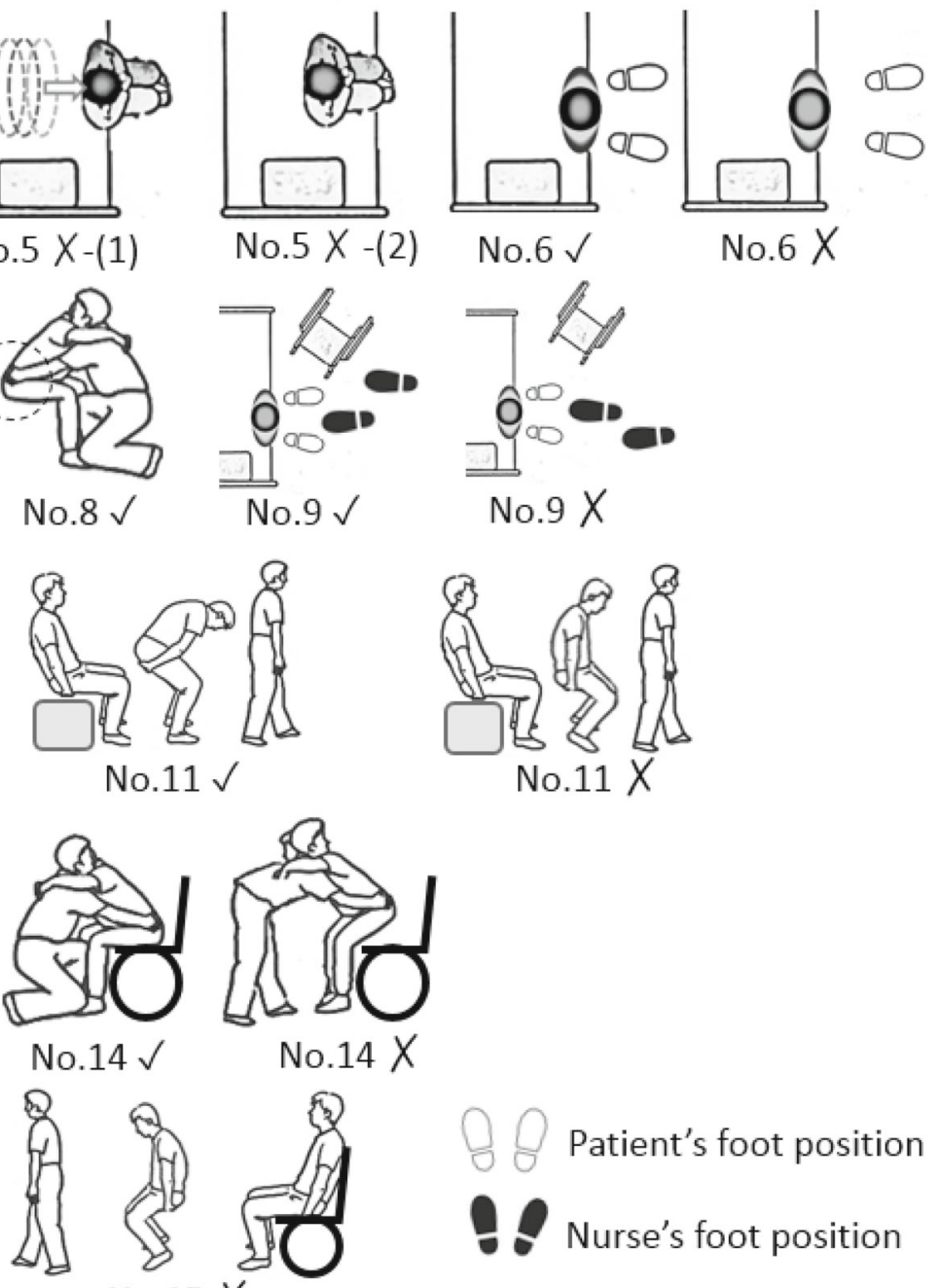

No.9X

No. $15 X$

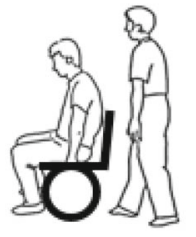

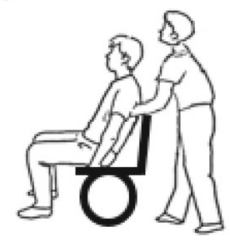

Fig. 3 The correct and incorrect methods for each step in the patient transfer procedure. The " $\checkmark$ " represents a correct method while the " $X$ " represents an incorrect method

in Tables 2 and 6. These eight parameters are marked with a cross sign in the table and are also illustrated in Fig. 4.

\subsubsection{Translational Acceleration of the Waist}

Translational acceleration can represent the dynamic translational movement of a patient, which is caused by forces exerted by a nurse during a transfer procedure. In previous 
Table 1 Transfer skill checklist

\begin{tabular}{|c|c|c|c|}
\hline Step & Correct Method & Incorrect Method & Effect on patient under incorrect method \\
\hline No. 1 & $\begin{array}{l}\text { Place the wheelchair at the } \\
\text { bedside and adjust the angle } \\
\text { to } 20-30^{\circ}\end{array}$ & $\begin{array}{l}\text { Place the wheelchair at the } \\
\text { bedside at a large angle }\end{array}$ & $\begin{array}{l}\text { The patient must be turned } \\
\text { at a large angle while turn- } \\
\text { ing them from the direction } \\
\text { of the bed to that of the } \\
\text { wheelchair }\end{array}$ \\
\hline No. 2 & $\begin{array}{l}\text { Place the wheelchair near the } \\
\text { bed }\end{array}$ & $\begin{array}{l}\text { Place the wheelchair very far } \\
\text { from the bed }\end{array}$ & $\begin{array}{l}\text { The patient must be moved } \\
\text { a long distance from the bed } \\
\text { to the wheelchair }\end{array}$ \\
\hline No. 3 & Apply the wheelchair brakes & Do not apply the brakes & $\begin{array}{l}\text { The wheelchair will slide } \\
\text { backward when the patient } \\
\text { sits down in the wheelchair }\end{array}$ \\
\hline No. 4 & $\begin{array}{l}\text { Place one of your feet } \\
\text { behind you and the other } \\
\text { foot between the feet of the } \\
\text { patient }\end{array}$ & - & - \\
\hline \multirow[t]{2}{*}{ No. 5} & \multirow[t]{2}{*}{$\begin{array}{l}\text { Enable the patient to sit on } \\
\text { the edge of the bed by shift- } \\
\text { ing the position of their bot- } \\
\text { tom }\end{array}$} & $\begin{array}{l}\text { 5-(1) Move the patient to the } \\
\text { edge by pulling the patient } \\
\text { straight without shifting } \\
\text { their bottom }\end{array}$ & $\begin{array}{l}\text { The patient's trunk will } \\
\text { not be rotated. Instead, the } \\
\text { trunk will be directly pulled } \\
\text { toward the edge of bed }\end{array}$ \\
\hline & & $\begin{array}{l}\text { 5-(2) Do not move the } \\
\text { patient to the edge of the bed }\end{array}$ & $\begin{array}{l}\text { The patient's trunk must be } \\
\text { bent down at a relatively } \\
\text { large hip angle to allow them } \\
\text { to stand up from a sitting } \\
\text { position at the inner side of } \\
\text { the bed }\end{array}$ \\
\hline No. 6 & $\begin{array}{l}\text { Adjust the patient's leg pos- } \\
\text { ture and move the patient's } \\
\text { ankle closer to the bed }\end{array}$ & $\begin{array}{l}\text { Move the patient's ankle far } \\
\text { from the bed }\end{array}$ & $\begin{array}{l}\text { The knee angle will become } \\
\text { smaller when the patient's } \\
\text { ankles are placed far from } \\
\text { the bed; the maximum value } \\
\text { of the knee angle also } \\
\text { becomes smaller during the } \\
\text { standing process }\end{array}$ \\
\hline No. 7 & $\begin{array}{l}\text { Place both arms of the } \\
\text { patient on your shoulders } \\
\text { and hug patient }\end{array}$ & $\begin{array}{l}\text { Do not place both arms of the } \\
\text { patient on your shoulders }\end{array}$ & $\begin{array}{l}\text { The patient's arms should } \\
\text { hang down during the turn- } \\
\text { ing process }\end{array}$ \\
\hline No. 8 & $\begin{array}{l}\text { Clutch the lower back of the } \\
\text { patient }\end{array}$ & - & - \\
\hline No. 9 & $\begin{array}{l}\text { Place your right foot behind } \\
\text { you and the left foot between } \\
\text { the feet of the patient }\end{array}$ & $\begin{array}{l}\text { Place your feet in incorrect } \\
\text { positions: left foot behind } \\
\text { you and right foot between } \\
\text { the feet of the patient }\end{array}$ & $\begin{array}{l}\text { The patient experiences } \\
\text { unstable movements, such } \\
\text { as lateral swaying, during } \\
\text { a turn from the bed to the } \\
\text { wheelchair }\end{array}$ \\
\hline No. 10 & $\begin{array}{l}\text { Squat down and lower your } \\
\text { waist to prepare to help the } \\
\text { patient stand up }\end{array}$ & $\begin{array}{l}\text { Do not bend your knees and } \\
\text { lower your waist }\end{array}$ & $\begin{array}{l}\text { The patient will be lifted up } \\
\text { rapidly with greater upward } \\
\text { acceleration }\end{array}$ \\
\hline No. 11 & $\begin{array}{l}\text { Make the patient lean for- } \\
\text { ward, then assist the patient } \\
\text { to stand }\end{array}$ & $\begin{array}{l}\text { Do not make the patient lean } \\
\text { forward first; make them } \\
\text { stand up vertically }\end{array}$ & $\begin{array}{l}\text { The patient's hip angle } \\
\text { extends without a flexion } \\
\text { while standing up because } \\
\text { the trunk was not bent }\end{array}$ \\
\hline No. 12 & $\begin{array}{l}\text { Use your left foot as a pivot } \\
\text { axis to help the patient turn } \\
\text { toward the wheelchair }\end{array}$ & - & - \\
\hline
\end{tabular}


Table 1 continued

\begin{tabular}{|c|c|c|c|}
\hline Step & Correct Method & Incorrect Method & Effect on patient under incorrect method \\
\hline No. 13 & $\begin{array}{l}\text { Place one of your feet } \\
\text { behind you and the other } \\
\text { foot between the feet of the } \\
\text { patient }\end{array}$ & - & - \\
\hline No. 14 & $\begin{array}{l}\text { Lower your waist to prepare } \\
\text { to assist the patient to sit }\end{array}$ & $\begin{array}{l}\text { Do not lower your waist but } \\
\text { bend your knees to assist the } \\
\text { patient to sit down }\end{array}$ & $\begin{array}{l}\text { The patient's hip angle } \\
\text { extends without a flexion } \\
\text { while sitting down because } \\
\text { the trunk is not bent }\end{array}$ \\
\hline No. 15 & $\begin{array}{l}\text { Lean the patient' trunk for- } \\
\text { ward while assisting the } \\
\text { patient to sit }\end{array}$ & $\begin{array}{l}\text { Do not allow the patient } \\
\text { to first lean forward before } \\
\text { assisting them to sit down }\end{array}$ & $\begin{array}{l}\text { Patient will rapidly sit down- } \\
\text { ward with increased down- } \\
\text { ward acceleration }\end{array}$ \\
\hline No. 16 & $\begin{array}{l}\text { Make the patient sit } \\
\text { against the backrest of } \\
\text { the wheelchair by leaning } \\
\text { the trunk down and pulling } \\
\text { back }\end{array}$ & $\begin{array}{l}\text { Lift the patient up vertically } \\
\text { and release the patient to } \\
\text { allow them to sit against the } \\
\text { backrest of the wheelchair }\end{array}$ & $\begin{array}{l}\text { The hip angle will first } \\
\text { extend and then flex when } \\
\text { following the incorrect } \\
\text { method, which differs from } \\
\text { the correct method, i.e., the } \\
\text { hip angle will first flex and } \\
\text { then extend }\end{array}$ \\
\hline
\end{tabular}

Table 2 Parameters obtained by measuring the SPs in [35]
Table 3 Level at which the difference is significant ( $p$-value) of translational acceleration measured at different locations of the SPs

\begin{tabular}{lll}
\hline Type of measurement & Measured locations & No. \\
\hline Translational acceleration & ${ }^{a}$ Waist & 1 \\
& Chest & 1 \\
Rotational speed & Both arms & 2 \\
& Both legs & 2 \\
Joint angle & Waist & 1 \\
& ${ }^{a}$ Chest & 1 \\
& Both arms & 2 \\
Both legs & Shoulders (extension/flexion) & 2 \\
& Shoulders (external/rotation rotation) & 2 \\
& ${ }^{a}$ Shoulders (abduction/adduction) & 2 \\
& Elbows (extension/flexion) & 2 \\
& ${ }^{a}$ Hips (extension/flexion) & 2 \\
& Hips (external/rotation rotation) & 2 \\
& Hips (abduction/adduction) & 2 \\
& ${ }^{a}$ Knees (extension/flexion) & 2 \\
& Ankles (plantarflexion/dorsiflexion) & 2
\end{tabular}

${ }^{a}$ Represents the determined parameters to be measured from the robot patient

\begin{tabular}{llllllll}
\hline Step & Value & Waist & Chest & R_arm & L_arm & R_leg & L_leg \\
\hline No. 3 & Peak-to-valley & 0.034 & 0.162 & 0.432 & 0.296 & 0.485 & 0.485 \\
No. 10 & Peak-to-valley & 0.494 & 0.572 & 0.901 & 0.612 & 0.535 & 0.854 \\
No. 14 & Peak-to-valley & 0.046 & 0.178 & 0.067 & 0.067 & 0.230 & 0.172 \\
\hline
\end{tabular}


Table 4 Level at which the difference of the rotational speed measured from different locations of the SPs is significant ( $p$-value)

\begin{tabular}{|c|c|c|c|c|c|c|c|}
\hline Step & Value & Waist & Chest & R_arm & L_arm & R_leg & L_leg \\
\hline No. 1 & Angular displacement & 0.091 & 0.023 & 0.040 & 0.056 & 0.057 & 0.073 \\
\hline No. 5-(1) & Variation of angular distance & 0.042 & 0.020 & 0.042 & 0.030 & 0.040 & 0.164 \\
\hline No. 9 & Min.-to-max. & 0.079 & 0.045 & 0.416 & 0.463 & 0.165 & 0.362 \\
\hline
\end{tabular}

studies [35], the translational acceleration was measured at six locations of SPs to investigate the effect of both correct and incorrect skills. Based on the comparisons in Table 3, the parameter measured from the waist reveals the most significant difference in the steps (Nos. 3, 10, and 14) related to upward/downward and front/back movements of the trunk. In addition, it indicates that the translational acceleration of the waist allows for a more effective evaluation of the steps related to standing and sitting compared with other locations.

The peak-to-valley value of the translational acceleration (z-axis), where the valley is subtracted from the peak value, can reveal the forces that are exerted on the patient. A single peak and valley is generated when acceleration occurs due to an inertial measurement unit inside the IMU sensor that senses the oscillation. For example, in step No. 10, if a nurse does not lower their waist while lifting the patient to a standing position, the patient will move upward more rapidly with an increased translational acceleration. Additionally, while attempting to seat a patient in a wheelchair, if a nurse follows an incorrect method and does not lower the waist (step No. 14), this leads to increased translational acceleration because the patient is not supported stably.

In addition, the translational acceleration ( $\mathrm{x}$-axis) experienced while sitting in the wheelchair in step No. 3 can reveal that the nurse has not applied the brakes on the wheelchair. If the brakes are applied before the patient is seated in the wheelchair, this will increase the peak-to-valley value of the translational acceleration measured when the patient stops moving backward. We measure the translational acceleration beginning at the waist of the patient because the nurse takes hold of the patient's waistband to move the patient during a transfer. Therefore, measurements from the waist can reveal the most sensitive movement.

\subsubsection{Rotational Speed of the Chest}

In our previous study [35], the rotational speed was measured at six different locations on the patient. Based on the analysis presented in Table 4, the rotational speed (z-axis) of the chest revealed the most significant difference in steps involving the rational movements of the patient. This is because the rotational speed measured from the chest (i.e., the upper trunk) can more sensitively reflect movements, such as unstable swaying or lateral rotation, of the upper body during rotation.
Therefore, among the six measured locations of rotational speed, the chest was determined to be the most sensitive.

The variation in angular distance, which is calculated using the rotational speed (z-axis) of the chest, can reveal how different transfer methods affect patients during a transfer to the edge of a bed in step No. 5. If the nurse follows incorrect method 5-(1) and directly pulls the patient to the edge of the bed without shifting the position of their bottom, there is no obvious variation in angular distance. In addition, the rotational speed (z-axis) can be used for inferring the correctness of nursing skill during pivot turning. For example, in step No. 1, the angular displacement was computed by multiplying rotational speed by time and performing a summation. The obtained angular displacement can illustrate the differences in the results obtained under correct and incorrect methods.

Also the min.-to-max. rotational speed value can represent the rotation-related motions of a patient during transfer. The min.-to-max. value is calculated by subtracting the minimum value from the maximum value, and its range represents the speed variations that occur while the patient is being turned. It was found that the min.-to-max. Value of the rotational speed during the turning process could illustrate the differences between the correct and incorrect methods. Accordingly, with incorrect foot placement of step No. 9, it is difficult for a nurse to turn the patient; thus the patient that cannot be smoothly and stably turned would be have a lager min.tomax. rotational speed.

\subsubsection{Joint Angle of the Shoulder, Hip, and Knee}

Based on the results in [35], the joint angles are essential when interpreting the change in a patient's position. Furthermore, more than one joint angle can reveal the significant difference in a single step. Thus, to minimize the parameters relating to the joint angle, we compared the level of significance of the difference obtained in the statistical analysis, as presented in Table 5. Finally, the joint angles of the shoulders (abduction/adduction), hips (flexion/extension), and knees (flexion/extension) were determined to assess the steps in which each of them exhibits the most significant difference. However, uninformative joint angles, such as the elbow, were excluded, as presented in Table 6 .

The hip and knee angles represent a patient's lower limb movements. For example, for the standing and sitting move- 


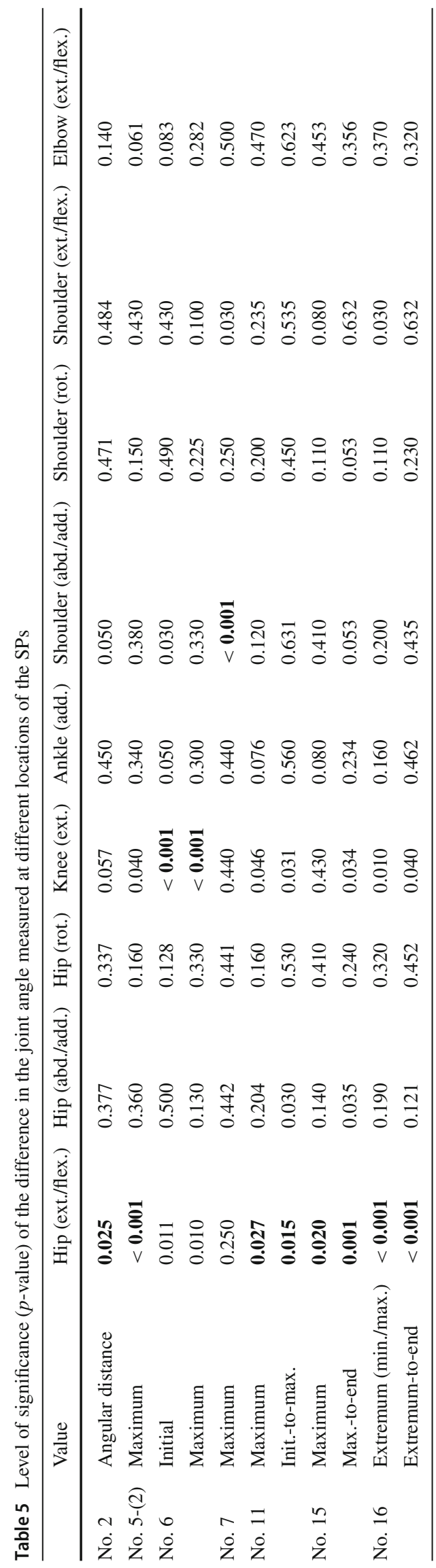

ments in step Nos. 5-(2), 11, and 15, the maximum hip joint angles are smaller when following incorrect methods. Additionally, the init.-to-max. angle of the hip joint is smaller when using the incorrect method described in step No. 11. Here, the initial angle is the angle before standing. Similar to step No. 6, the initial, which is the angle measured after the nurse adjusts the patient's ankle before standing, and maximum angle of the knee joint reveal how the correct and incorrect transfer methods can affect the patient. When following the incorrect method, the initial and maximum angles become smaller. Similar to step No. 2, there is an increase in the variation in the angular distance of the hip joint if the wheelchair is placed at a distance from the bed as such a placement forces the patient to walk additional steps, which increases the variation in the hip angle.

In step No. 15, the common mistake is assisting the patient to sit on the wheelchair without performing downward leaning of their trunk. This incorrect method leads to a decrease in the maximum and max.-to-end hip joint angles. Here, the end angle is the angle measured after completion of this step's sitting procedure. The last step, i.e., No. 16, involves adjusting the patient's posture, making them sit against the backrest of the wheelchair. The correct method is to hold both arms of the patient, make the patient lean forward, and then pull the patient back to sit against the backrest. In the incorrect method, the patient is lifted upward by their armpits and then released to lay on the backrest. The extremum (max./min.) and extremum-to-end values of the hip angle illustrate the differences between the correct and incorrect methods. The correct method yielded a minimum value while the incorrect method resulted in a maximum value. Also, the extremumto-end value, which represents the variation in the hip angle from the extremum value to the end when the patient lays on the backrest, yielding a smaller value when using the incorrect methods. Furthermore, the shoulder angle can be used to infer the correctness of the nursing skill during the patient's upper limb placement in step No. 7.

\section{Development of a Robot Patient}

In our previous studies [32], patient movements were simulated through the development of a robot patient and controlling methods. To integrate an evaluation system into the robot patient, we improved the prototype robot patient by installing IMU and angular position sensors to measure the parameters used for evaluation.

\subsection{Hardware}

The robot comprises a head, upper limbs, waist, hips, and lower limbs, as shown in Fig. 5. The size of the robot was 158 $\mathrm{cm}$, which was designed considering the height of an aver- 
Table 6 The parameters measured by the robot patient to evaluate a nurse's transfer skills

\begin{tabular}{llll}
\hline Step & Effect on & Measure parameter & Value \\
\hline No. 1 & Turning toward the wheelchair & Rotational speed of the chest (z-axis) & Angular displacement \\
No. 2 & Moving toward the wheelchair & Joint angle of the hip (flexion/extension) & Variation of angular distance \\
No. 3 & Sitting down on the wheelchair & Translational acceleration of the waist (x-axis) & Peak-to-valley \\
No. 5 -(1) & No. 5 & Rotational speed of the chest (z-axis) & Variation of angular distance \\
No. 5 -(2) & Standing up & Joint angle of the hip (flexion/extension) & Init.-to-max. \\
No. 6 & No. 6 \& Standing up & Joint angle of the knee (flexion/extension) & Init. \& max. \\
No. 7 & No. 7 & Joint angle of the shoulder (abduction/adduction) & Maximum \\
No. 9 & Turning toward the wheelchair & Rotational speed of the chest (z-axis) & Min.-to-max. \\
No. 10 & Standing up & Translational acceleration of the waist (z-axis) & Peak-to-valley \\
No. 11 & Standing up & Joint angle of the hip (flexion/extension) & max. \& Init.-to-max. \\
No. 14 & Sitting down & Translational acceleration of the waist (z-axis) & Peak-to-valley \\
No. 15 & Sitting down & Joint angle of the hip (flexion/extension) & Max. \& Max.-to-end \\
No. 16 & No. 16 & joint angle of the hip (flexion/extension) & Extremum (min./max.) \& \\
& & & Extremum-to-end
\end{tabular}

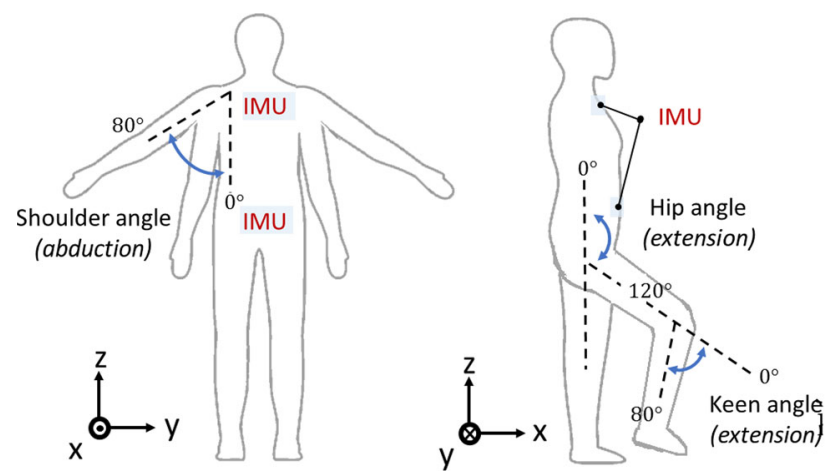

Fig. 4 The determined parameters to evaluate a nurse's transfer skills

age Japanese female. Because a heavy load could increase the possibility of injuring the nurse lower back during incorrectly executed skills [39], the robot's weight was temporarily reduced to $32 \mathrm{~kg}$, which is $60 \%$ of the average weight of a Japanese adult female of $53 \mathrm{~kg}$. If necessary, the weight can be adjusted by adding weight units to a hollow space within the robot's chest and limbs.

The robot patient was developed with 18 degrees of freedom (DoFs) in total to reproduce the movements required to learn the transfer skills. Four DoFs were implemented for each robot arm using servomotors. These include the pitch, roll, and yaw rotation of the shoulder and pitch rotation of the elbow. Additionally, each lower limb was designed with four DoFs, representing the pitch and roll rotation of the hip and pitch rotation of the knee and ankle. The pitch rotation of the hip joint was developed using a motor connected to a reduction gear. The roll rotation reproduces passive adjustments performed by nurses to correct the sitting posture of a patient. Thus, we developed a free rotation joint without a motor. Furthermore, the waist joint was developed with two pitch-and-roll DoFs using a motor and harmonic drive. The knee joint was equipped with an electromagnetic brake, which was applied when the robot assumed a standing posture. Finally, the ankle joint was designed as a free joint to allow posture adjustments on the footrest of the wheelchair. All mechanisms were connected to an ARM development board through RS485 ports. The board was fixed to the chest of the robot. A speaker and a voice recognition device were installed to respectively relay the voice of the robot and receive commands from the nurses.

To measure the joint angle, servo motor encoders were employed on the shoulder and hip joints. In addition, an angular position sensor was installed on the knee joint to measure the joint angle. In the working of the angular position sensor, the rotation causes changes in the resistance, which subsequently get converted to changes in the output voltage that can be computed as a corresponding angle. The encoder also generates different pulses by employing a rotating code disc during rotation and transmitting it to an angular position. The encoders and angular position sensor were also connected to the ARM development board through RS485 ports. Furthermore, to measure the translational acceleration of the waist and rotational speed of the chest, we used two six-axis IMU sensors. An IMU is based on MEMS technology. Furthermore, it collects both translational acceleration and rotational speed based on the principle of the piezoelectric effect. Each IMU sensor was connected to a Raspberry Pi board through an SPI serial communication. Both Raspberry Pi boards were placed on the chest, such that one was connected to the ARM development board, as shown in Fig. 5. To minimize the need for wired connections, a router was used to connect both Raspberry Pi boards to external computers. 


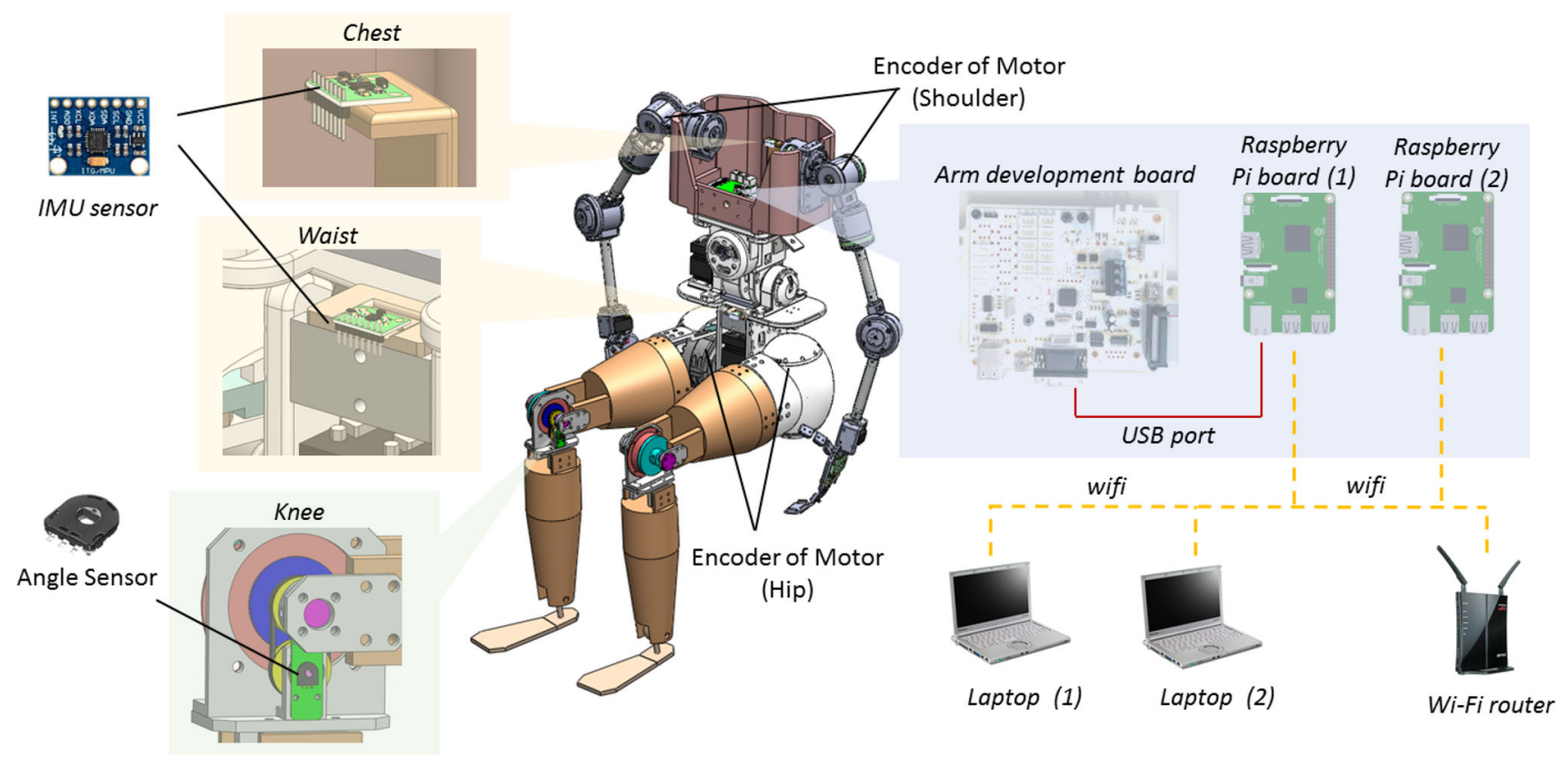

Fig. 5 The configuration of the developed robot

\subsection{Software}

To reproduce patient actions, Huang et al. [31] proposed a robot patient controlling method. The action planning for the robot patient involved five steps: preparing to stand, standing up, turning, sitting down, and sitting. Voice commands and limb posture of the robot patient were used by the nurse to identify the steps being executed. The trigger for preparing to stand is the shoulder angle that occurs when the nurse places the arm of the robot patient on their shoulder before standing up. The trigger that begins to turn after standing up is the knee angle that extends to $10^{\circ}$, which represents the end of the standing up step. The trigger to sit down is the voice command "Please sit down." The trigger for sitting occurs when the angle of the knee joint indicates a flexion greater than $80^{\circ}$.

To observe and analyze patient movement, we must ensure that all data are measured and saved within the same time series. Specific values must be extracted from the data at certain times to ensure an accurate comparison. For example, the peak-to-valley value may of translatioinal acceleration require extraction at the exact moment the robot sits down in the wheelchair. Therefore, an algorithm to measure and save the data in a synchronized manner was implemented using three programs in the ARM development and Raspberry Pi boards. Figure 6 shows a flowchart of the algorithm. Raspberry Pi board (1) was configured as the master board that receives angle data delivered from the ARM development board, as well as the triggers sent from Raspberry Pi board (2). The rotational speed of the chest and joint angles were stored in Raspberry Pi board (1) while the translational acceleration of the waist was saved in Raspberry Pi board (2). The communication between the Raspberry Pi boards was performed using Wi-Fi while communication between the Raspberry Pi and ARM boards was achieved with a USB cable. Furthermore, all data were recorded with a time stamp, enabling the segmentation of the time series data. As the transfers being evaluated are not typically performed at high speeds, we selected a sampling rate of $20 \mathrm{~Hz}$. The synchronization capability of the proposed algorithm was verified. The time tolerance between different data measuring identical action was $10 \mathrm{~ms}$, which was within the range of allowable error.

\section{Experiment}

\subsection{Purpose}

Differing from the previous experiment, which employs the nursing teacher SPs and measures thirty parameters, the following experiment aims to verify if the proposed evaluation method, which uses a robot patient with lesser parameters, is feasible. Furthermore, we aim to analyze the similarities between the robot patient and the SP interactions during transfer procedures to validate the simulated learning carried out using the robot patient. 


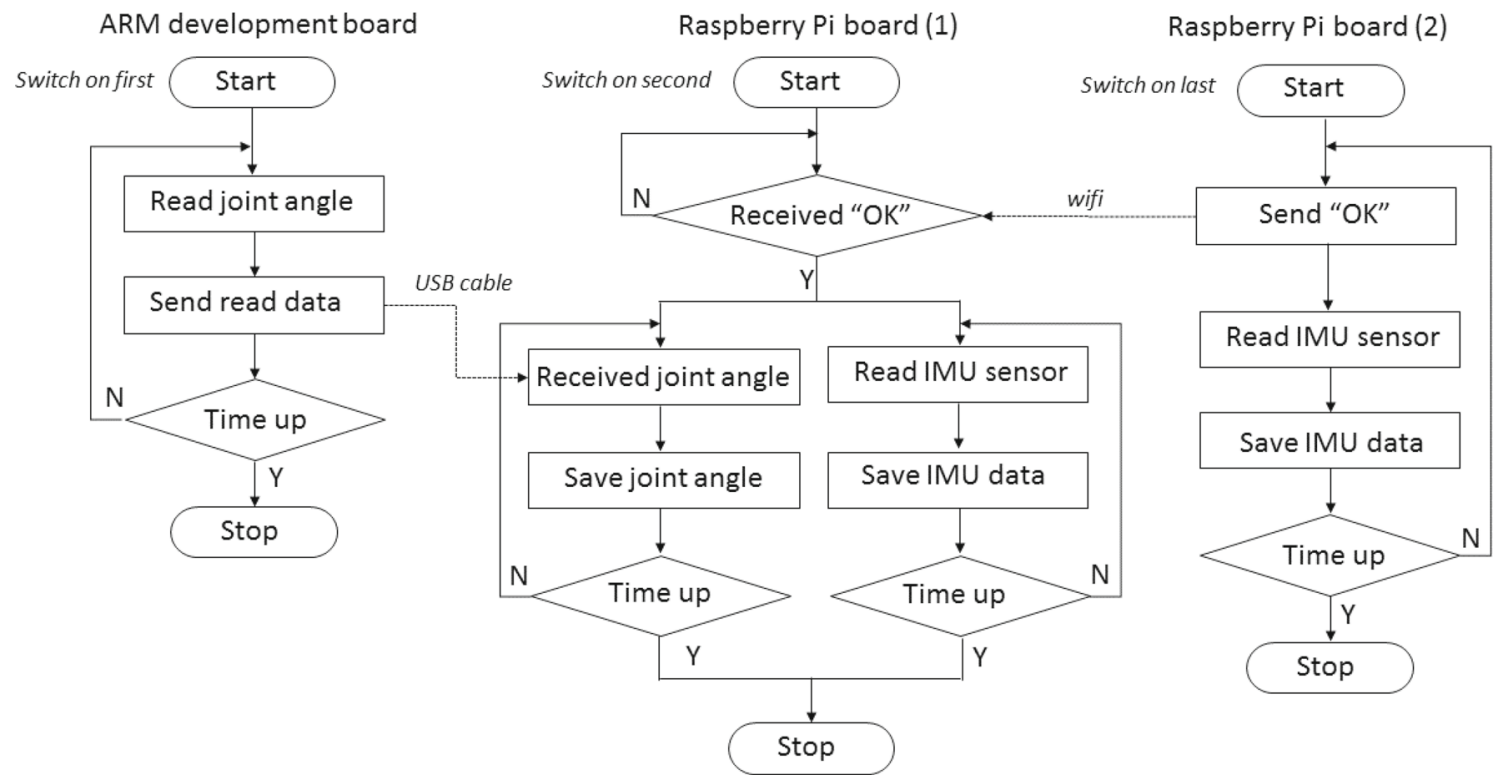

Fig. 6 A flowchart of the proposed measuring system

\subsection{Participants}

Four experienced nursing teachers, two males and two females, participated in the experiment. The age was $48 \pm$ 4.55 years (mean \pm SD), a height of $168.5 \pm 12.16 \mathrm{~cm}$ (mean \pm SD), and a weight of $58 \pm 9.9 \mathrm{~kg}$ (mean \pm SD). All nursing teachers possess clinical experience in hospitals and teaching experience at nursing schools. They were asked to conduct both correct and incorrect methods. The experiment was approved by the Ethics Committee at the University of Tokyo. All participants provided their written informed consent in advance.

\subsection{Experimental Setting and Procedures}

The environmental setting for the patient transfer included a bed and wheelchair. The height of the bed was set to $50 \mathrm{~cm}$, which allowed the knees of the patient to bend at $90^{\circ}$ while the patient sat on the bed. A camera was installed to record the experimental trial, which was used as a reference to extract the time series data for the translational acceleration, rotational speed, and joint angle. In addition to the participants, there were two staff members in charge of remotely operating the Raspberry Pi boards through two laptops. Another staff member stood beside the robot patient to handle emergent incidences, such as accidental falls.

At the beginning of the experiment, an orientation of the robot patient was performed. The teachers were then allowed to gain experience with the developed robot patient for a brief period. During this time, all participants were asked to perform the steps of the correct and incorrect methods, as shown in Fig. 7. Each method was performed twice. Based

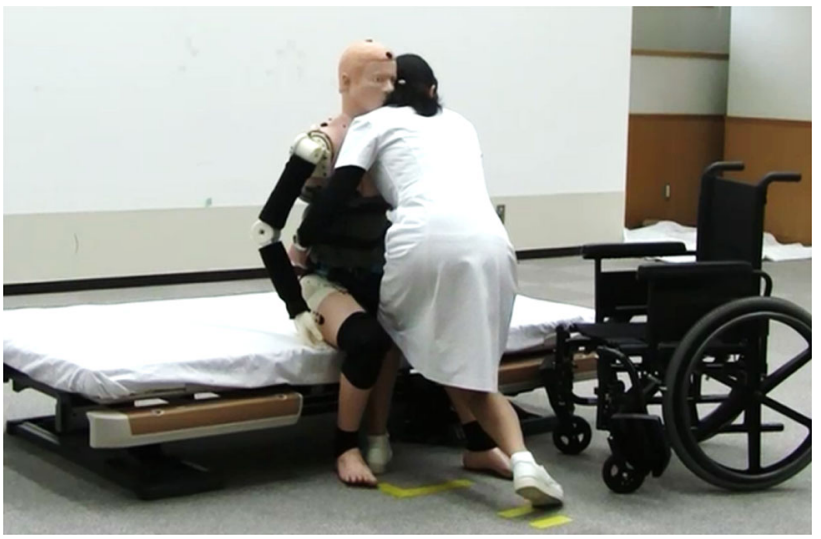

Fig. 7 Experimental trials conducted by the nursing teachers with the robot patient

on concerns that students can be considered novices without clinical and teaching experience, they have difficulties repeatedly reproducing both correct and incorrect methods. This may also lead to a variation in the difference of the incorrect methods, which are common mistakes based on the clinical experience of the nursing teachers. Therefore, we recommend that the nursing teachers conduct both the correct and incorrect methods. In addition, to avoid the order effect, the trial order was rebalanced for each participant.

After completion of the transfer trials, the time series data were extracted from the raw data. The extracted data generated during the performance of correct and incorrect methods were subsequently compared and analyzed. 


\subsection{Results}

The experiment results were analyzed by using the t-test to determine whether a significant difference exists between the correct and incorrect methods. In addition, Tukey's HSD was employed to modify the level of significance between evaluation parameters. Furthermore, the specific values in the time series data, such as the maximums, were extracted from the row data. For the analysis, the input of each teacher represented the average values from two repeated trials. Tables 7, 8, 9 list the experimental results, the SD value of the four participants in each method, and the $p$-value. Also, the effect size of Cohen's $d$, which is used to estimate the difference between two samples rather than confounding with the sample size, was obtained. This suggests that the value $d>0.8$ should be considered as a large effect size, which implies that the difference is hardly affected by sample size. In addition, all steps with significant differences $(p<0.05)$ reveal that the effect size of the designed experiment was large.

The results illustrate significant differences in the incorrect methods No. 1, 3, 5-(1), 6, 7, 11, 14, 15, and 16. And also the both correct and incorrect methods had identical effects on the robot and SP.

In four incorrect method of the checklist (i.e., Nos. 2, 5-(2), 9 , and 10), we were unable to assess by using the determined parameters due to non-significant differences. Moreover, in most of these steps, the robot patient and SP exhibited different effects when both were treated with the incorrect method (or certain effects were also different with the correct methods). The possible reasons for the non-significant differences between the correct and incorrect methods, as well as inconsistencies between robot patient movement and the SP, are presented in the discussion section.

\subsubsection{Translational Acceleration of the Waist}

The translational acceleration of waist reveals significant differences between the correct and incorrect methods for step Nos. 3 and 14. In step No. 3, a significant difference $(p=0.040)$ between correct and incorrect methods were noted during seating down on the wheelchair. Additionally, in steps No. 14 , a significant differences $(p=0.021)$ were also observed, According to Fig. 8, when the incorrect method was followed in step No. 14, the measured peak-to-valley value (z-axis) was larger than that measured for the correct method.

However, in step No. 10, a non-significant difference between the correct and incorrect methods was observed $(p=$ 0.899). This result differs from [35], who reported an SP that exhibited a higher translational acceleration with the incorrect method. The discussion section proposes a solution for evaluating this step.

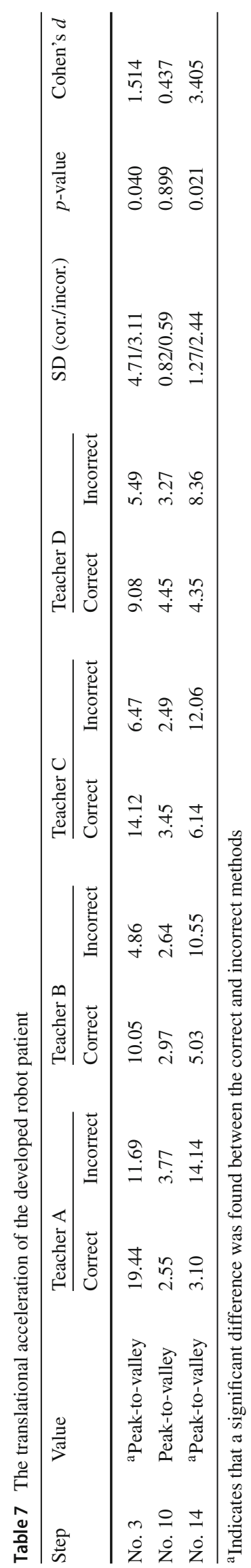



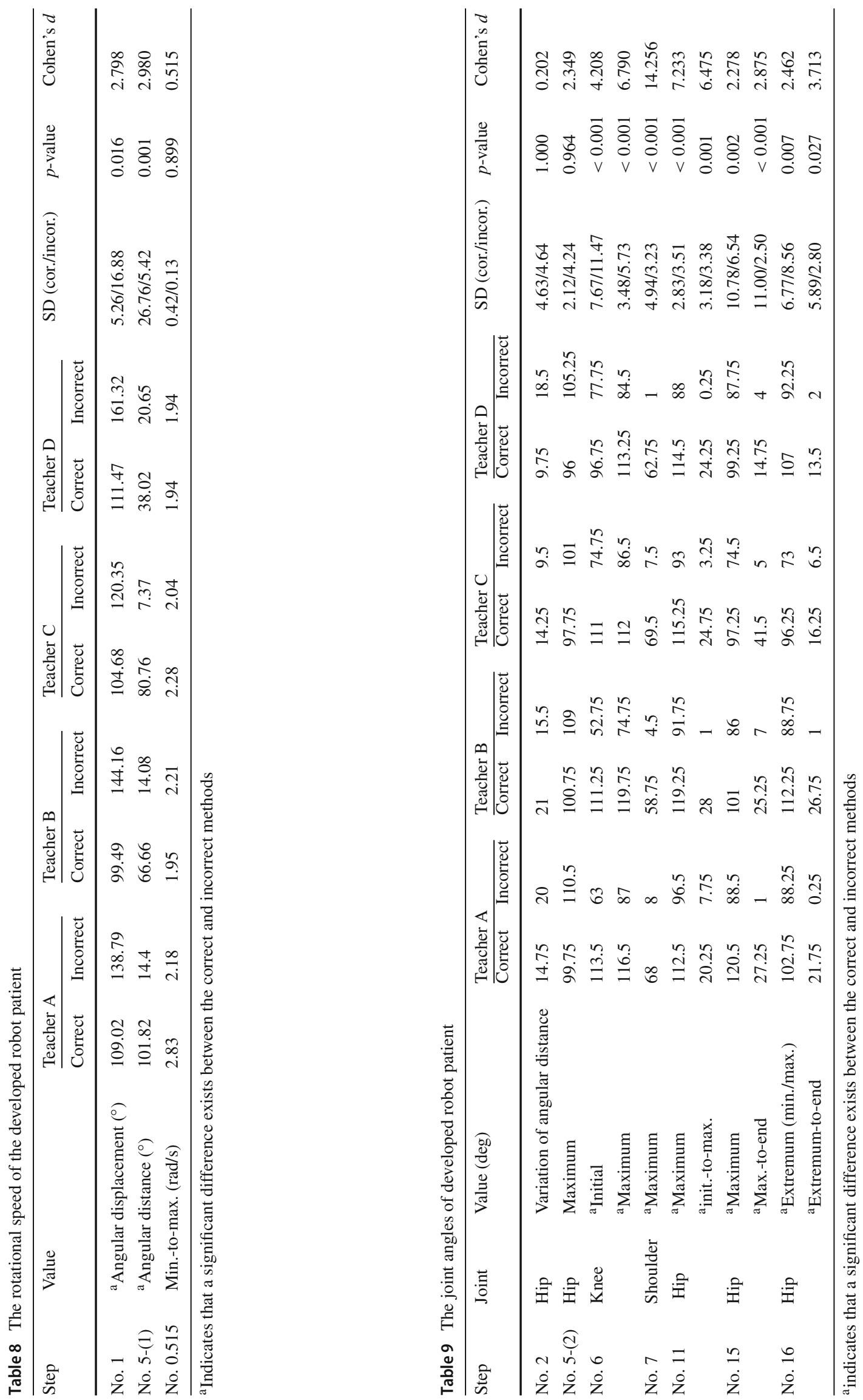


\subsubsection{Rotational Speed of the Chest}

Significant differences in rotational speed under correct and incorrect methods were noted in steps Nos. 1 and 5. In step No. 1, which relates to placing the wheelchair at a certain angle, a significant difference was noted $(p=0.016)$ in the rotational angular displacement, and its value becomes larger under the incorrect method. In addition as shown in Fig. 9, the variation in rotational speed becomes smaller than correct method. This causes the variation in angular distance computed from rotational speed exhibits a significant difference ( $p=0.001)$ under the incorrect method 5-(1), and also reveals a smaller value than correct method.

In contrast, in step 9, the correct method requires nurses to place their right leg behind them, and place their left leg between the feet of the patient, while in the incorrect method nurses place their feet in the opposite positions. However, a non-significant difference between the correct and incorrect methods was found during pivot turning $(p=0.899)$.

\subsubsection{Joint Angle}

Significant differences in joint angles were observed in five steps, allowing us to infer the correctness of nursing skills. The incorrect methods for step Nos. 6, and 11 affected the joint angle of the patient's lower limbs during standing. In step No. 6, a significant difference was observed at the initial knee angle $(p<0.001)$, which is the knee angle observed after the nurse moved the patient's ankles toward the bedside. We also observed a significant difference in the maximum angle $(p<0.001)$ during standing. When the ankle was placed too far from the bed, the initial and maximum angles became smaller. In step No. 11, in which the nurse assisted the patient to stand, the maximum angle of the hip joint $(p<0.001)$ and variation from the init.-max. ( $p=0.001$ ) of the hip angle had significant differences. As shown in Fig. 10, when following the correct method, these two values are larger than when following the incorrect method.

In step No. 7, the maximum angle of the shoulder became smaller when the incorrect method was followed, exhibiting a significant difference $(p<0.001)$ from the correct method. This occurred because the patient's arms were raised and placed on the nurse's shoulders. In the sitting process of step No. 15, we observed a significant difference on both the maximum $(p=0.002)$ and max.-to-end $(p<0.001)$ angles of the hip joint. Both angles became smaller with the incorrect method. In the last step, i.e., No. 16, in which the patient's posture was adjusted to be seated against the backrest of the wheelchair, a significant difference was observed in the extremum value $(p=0.007)$ of the hip joint. The maximum extremum value was obtained using the correct method while the minimum extremum was found using the incorrect method. Moreover, the variation between the extremum-toend angle also revealed a significant difference $(p=0.027)$.

However, the variation in the angular distance of step No. 2 did not yield a significant difference $(p=1.000)$. In addition, in step No. 5-(2), although we observed a larger hip angle during standing when the nurse used the correct method by not moving the patient to the edge of the bed, the difference in the hip joint angle $(p=0.964)$ is insignificant. And such results are discussed in the following section.

\section{Discussion}

Based on the determined parameters (i.e., the translational acceleration of the waist, rotational speed of the chest, and joint angles of the shoulder, hip, and knee), we can distinguish the correctness of the nursing skills in nine of the incorrect methods (Nos. No. 1, 3, 5-(1), 6, 7, 11, 14, 15, and 16.). The desired results were obtained in this study, because less informative and redundant parameters were removed and were not measured. Thus, the final eight parameters that were determined make it possible to sensitively assess the effect of correct and incorrect skills on the robot patient. Such results prove that the parameter determination and indirect evaluation method, in which sensors are only installed on the patient (and not on the trainees or in the environment), are practical for evaluating nurse transfer skills. The obtained results also support the results obtained in our previous study [35]. Moreover, the relatively small number of determined parameters avoids the need for redundant sensors and simplifies robot development because this only requires IMU and angular position sensors. Among the determined parameters, the knee and hip angles allow us to infer nursing skill correctness for four steps (Nos. 6, 11, 15, and 16), which all relate to standing and sitting. Therefore, the joint angles of a patient are crucial elements that reveal lower limb body mechanics. Furthermore, this experiment provides explicit evidence of the influence that nursing skill has on the patients. In addition to being useful for evaluating nursing skills, the quantitative data measured from the patients are essential in practical training for clinical examinations, where the accessibility to actual patients is relatively low.

In this study, eight parameters were determined based on the results obtained from SPs in the pre-work [35], and we expected these parameters to reveal a significant difference between the correct and incorrect methods on the checklist; however, four of the steps (i.e., Nos. 2, 5-(2) 9, and 10) exhibit insignificant differences. This result is plausible because of the different movements when both the robot patient and SPs were handled using incorrect methods (or certain steps that were also different even though the correct method was used). As a result, those steps cannot be used to evaluate the nursing skills by using the parameters that were determined using the experimental results obtained with the SPs. 


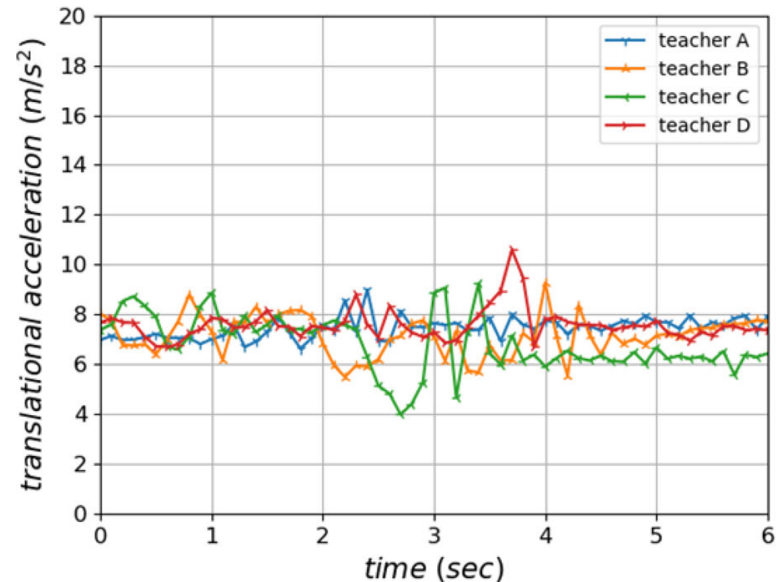

(a)

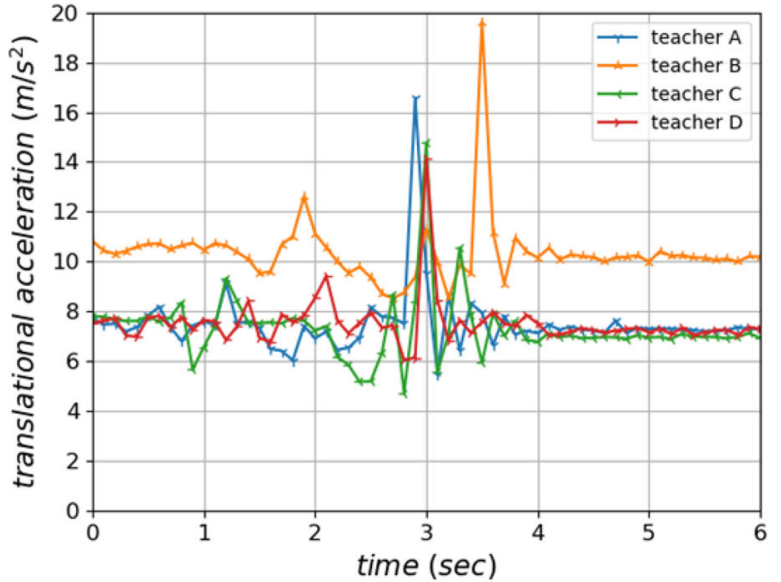

(b)

Fig. 8 The translational acceleration while sitting according to step No. 14 in (a) the correct method and b the incorrect method

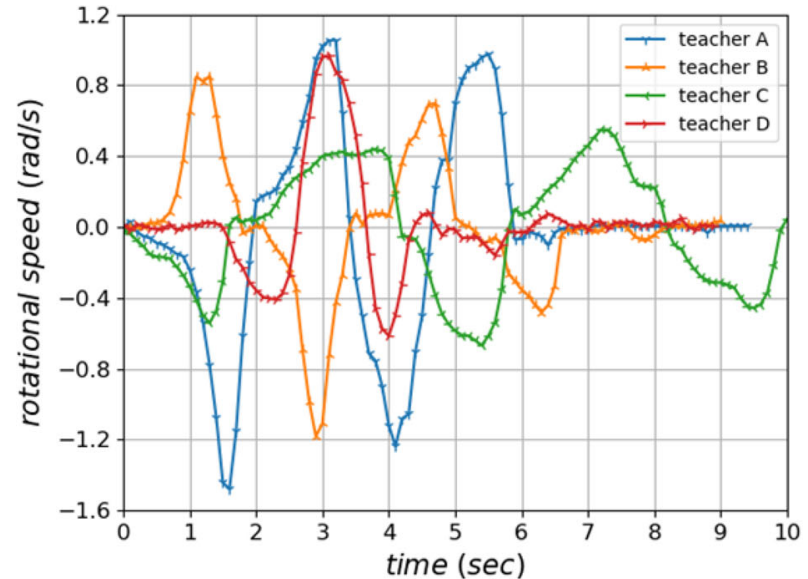

(a)

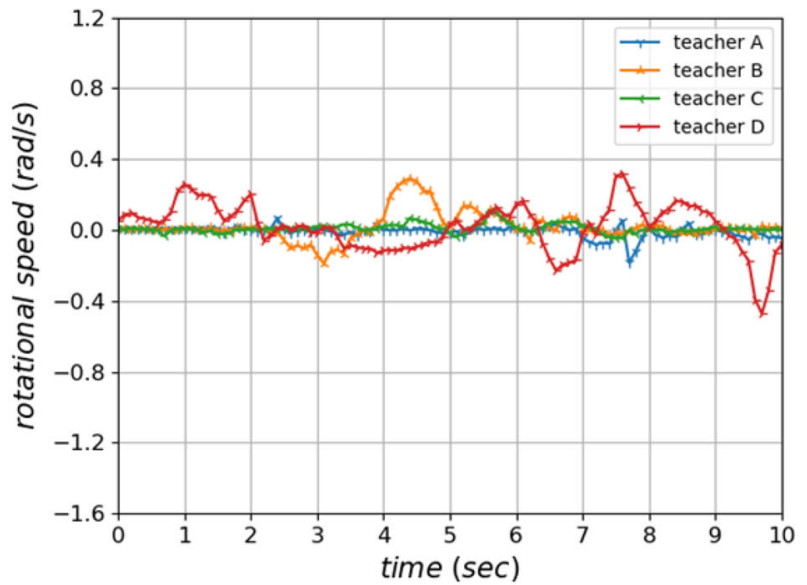

(b)

Fig. 9 The rotational speed while moving the patient to the edge of the bed according to step No. 5 of (a) the correct method and $\mathbf{b}$ the incorrect method 5-(1)

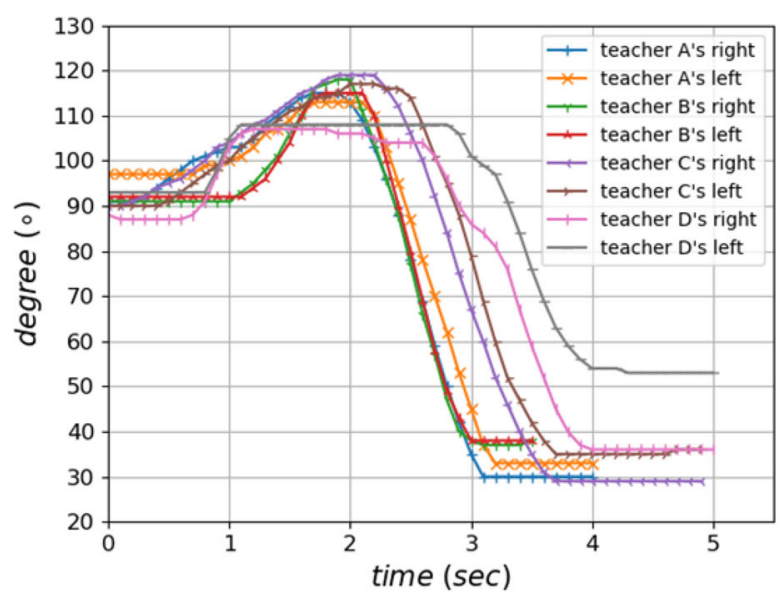

(a)

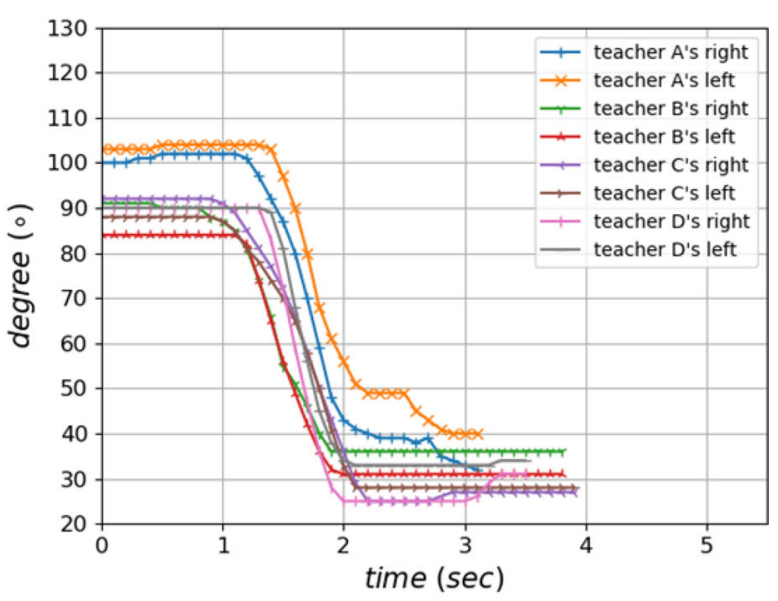

(b)

Fig. 10 The hip angle during the standing process using step No. 11 of (a) the correct method and $\mathbf{b}$ the incorrect method in 
The main differences between the SP and robot patient may be due to the mechanical design of lower limb joint. Originally, the lower limb of the robot was developed with a passive joint (i.e., a brake) to simulate a paralysis patient, differentiating them from the SPs portrayed by healthy individuals. According to experiential results obtained with an SP [35], a transfer from a bed to wheelchair resulted in a larger variation in the hip angular distance if the nurse placed the wheelchair too far from the bed in step No. 2 because the patient was required to walk a longer distance, and, thus, take more steps. However, the robot patient developed with the passive joints on the lower limbs could not engage in such walking behaviors, which arguably resulted in a non-significant difference between the correct and incorrect methods of step No. 2 for the robot patient. To assess step No. 2, we conceived a solution employing a tracking algorithm and IMU sensors. For the correct and incorrect methods, there was a significant difference in the transfer distance between the bed and wheelchair, which can be computed by the IMU tracking algorithm. Although such approaches have been widely applied, future studies must still address issues that relate to optimization tuning, noise levels, and IMU sensor placement before their implementation. We plan to address these issues in our future studies to improve the proposed evaluation system.

The other insignificant difference in the hip angle was observed in step No.5-(2). Although the same tendency was observed for each participant in the experiment, namely a larger maximum hip angle for the incorrect method and smaller maximum hip angle for the correct method, the difference is insignificant. The patient's trunk needs to be bent downward to a greater extent when the patient is not moved to the edge of the bed before being assisted to stand up. But hip angle obtained from the robot patient was not bent as obviously as SPs. And it is probably owning to that the standing behavior requires voluntary force to support the patient's weight is hardly to reproduced by the robot patient only developed with passive joint of lower limbs. Thus, to build a more reliable system to assess the incorrect method, another type of measurement had to be employed to determine the forward translational acceleration (x-axis) of the waist. This was necessary because, when the incorrect method was used, the patient was not moved to the edge of the bed; therefore, almost no forward translational acceleration occurred before standing up, i.e., $0.46 \pm 0.086 \mathrm{~m} / \mathrm{s}^{2}$ (mean $\pm \mathrm{SD}$ ). In contrast, for the correct method, a larger value of $6.04 \pm 1.124$ $\mathrm{m} / \mathrm{s}^{2}$ (mean $\pm \mathrm{SD}$ ) was measured for the forward translational acceleration. Accordingly, a significant difference ( $p$ $=0.021$ ) was obtained, the same as the difference that was previously found for the SPs [35].

In addition, passive joint design may also contribute to a non-significant difference in step No. 10. In this step, the correct method requires the nurse to squat down and lower their waist before assisting the patient to stand, whereas the incorrect method does not specify such preparations. According to [35], for the correct method, the assistance provided to the SP for standing included an increased upward translational acceleration. This plausibly occurred because the SP was simulated by a healthy individual who can voluntarily stand with an external supporting force from the nurse. In addition, when the nurse lowered their waist and squatted down, they exerted a greater force to lift the patient. These results were only observed when measuring SP movements completed by healthy individuals, i.e., not when measuring robot patient movements developed with passive joints to simulate a paralysis patient. One solution is to investigate whether other measured data can be used to classify nursing skill against both a paralysis patient simulated by a robot and a healthy patient portrayed by a healthy individual. Eventually, we found that the forward translational acceleration ( $\mathrm{x}$-axis) of the waist can yield a significant difference ( $p=$ 0.031 ) between the correct and incorrect methods with the robot patient. This parameter has a larger value $8.962 \pm 1.068$ $\mathrm{m} / \mathrm{s}^{2}$ (mean $\pm \mathrm{SD}$ ) when the correct method is used, and a smaller value for the incorrect method $3.607 \pm 0.731 \mathrm{~m} / \mathrm{s}^{2}$ (mean $\pm \mathrm{SD}$ ). Additionally, a difference was also observed for the SP by analyzing the results reported in [35].

In the experimental results reported in [35], step No. 9 (which pertains to the nurse's foot placement) is characterized by a difference in the rotational speed of the chest based on limited data from a single trial of the correct and incorrect methods involving two participants. In these trials, the min.-to-max. of the rotation speed increased during the turning process as a result of the nurse's incorrect feet placement. However, according to the results of this study, there is a non-significant difference between the correct and incorrect methods of this step. Moreover, no other measured parameters yielded significant differences during the turning process. According to [34], a wide, staggered stance with the left or right foot forward causes differences in the lumbar shear and compression force during sudden loading, such as when lifting the patient to stand up. Thus, we reasonably suspect that foot placement may cause a significant difference during the standing process, as opposed to the turning process. We will verify this as an extension in future studies.

Based on the evaluation system prototype introduced into the robot patient, we can firstly distinguish between the common incorrect methods summarized in the checklist for the patients affected with weakness in lower limbs. Furthermore, to ensure that the correct and incorrect methods can be appropriately executed, both methods are conducted by nursing teachers instead of their students. However, in a real clinical training environment, the students, especially novices, may exhibit a wide range of incorrect actions, which are probably not included among the incorrect methods determined to give rise to the most common mistakes found in this study. 
However, at present, both the correct and incorrect methods listed in the checklist were verified as the first step in our progression. Future extension of this work to identify other incorrect methods used by the students would enable us to obtain a clear blueprint as a result of further observation during additional real clinical training.

As an initial stage to integrate the robot and the assessment, we first aim to work with patients who are specifically affected by weak strength rather than healthy individuals, during the transfer task. In addition, the present assessment only addressed the common mistakes of nursing students based on the clinical experience of nursing teachers.

Furthermore, because the effect of the level of skills on a patient's movement is essential for the evaluation, cases in which the nurses are unable to move the robot patient, or their assistance does not enable the patient to move, remain difficult to assess. Thus, those situations are not considered in this study. Furthermore, incorrect methods that do not result in the patient being moved could perhaps cause the trainees to become injured. Thus, when employing the developed robot patient for clinical training, basic orientation such as that implemented in this study is necessary.

\section{Conclusions and Future Work}

In this study, we integrated a robot patient equipped with an IMU and angular position sensors with a transfer skill evaluation system, with the goal of improving nursing student education in understaffed schools. By referring to the experimental results obtained with a simulated patient [35], we determined that the translational acceleration of the waist, the rotational speed of the chest, and the joint angles of the shoulder, hip and knee of the robot patient should serve as the parameters for nursing skill assessments. The prototype robot patient reported in [32] was improved to measure these parameters. In addition, a synchronized algorithm was proposed to measure and record the parameters. An experiment was conducted with four nursing teachers who were asked to perform both the correct and incorrect patient transfer methods.

According to the results, the translational acceleration of the waist can be used to evaluate two of the transfer steps while the rotational speed of the chest can be used to distinguish between the correct and incorrect methods in two of the transfer steps. Joint angles can be used to classify the correct and incorrect methods in five of the steps. In these steps, the nurse transfer skills contribute to significant differences between the results of the correct and incorrect methods. In addition, these differences have an identical effect on both the robot patient and SP. This shows that the developed robot patient can be used in transfer skill training. However, there are three steps where nurse skills cause different impacts on the robot patient and SP. As a result, we were unable to use the determined parameters to distinguish between the correct and incorrect methods. The solutions required to assess these steps on the robot patient include using other frontward transnational acceleration directions and employing a tracing algorithm in conjunction with an IMU.

In future studies, we will implement an algorithm to track distances using the IMU on the robot patient to ensure the evaluation of additional steps. We also plan to examine how patients are affected when nurses place their feet in incorrect positions when assisting patients to stand. In addition, we will conduct an experiment with a larger number of participants to obtain further statistical agreement and determine the threshold of each step. Furthermore, we intend to measure the effectiveness of learning and skill improvement of the nurses after they have practiced using the developed robot patient and compare the results by practicing with actual patients. In addition, the transfer of learnings from the robot patient to the actual patient should be addressed. Preliminary approval of patients suffering from weakness of the lower limbs was obtained for this study; therefore, we plan to continue this work by including more patients with other diseases in future work.

Acknowledgements This work was partially supported by JSPS KAKENHI Grant Number 15H02761 and 26120006. Hardware from the following companies was used in the study: Futaba Co., Ltd. (servomotors), Moog Animatics Co., Ltd. (motor), Harmonic Drive Co., Ltd. (reduction gear, harmonic drive), Miki Co., Ltd. (electromagnetic brake), ARM Co., Ltd. (ARM development board), TIGAL KG Co., Ltd. (voice recognition device), Alps Electric Co., Ltd. (angular position sensor), and TDK Co., Ltd. (IMU sensors).

\section{Compliance with ethical standards}

Conflict of interest The authors declare that they have no conflict of interest.

Open Access This article is licensed under a Creative Commons Attribution 4.0 International License, which permits use, sharing, adaptation, distribution and reproduction in any medium or format, as long as you give appropriate credit to the original author(s) and the source, provide a link to the Creative Commons licence, and indicate if changes were made. The images or other third party material in this article are included in the article's Creative Commons licence, unless indicated otherwise in a credit line to the material. If material is not included in the article's Creative Commons licence and your intended use is not permitted by statutory regulation or exceeds the permitted use, you will need to obtain permission directly from the copyright holder. To view a copy of this licence, visit http://creativecomm ons.org/licenses/by/4.0/.

\section{References}

1. Mba CJ (2010) Population ageing in ghana: research gaps and the way forward. J Aging Res 56:98

2. Belikov AV (2018) Age-related diseases as vicious cycles. Ageing Res Rev 98:115 
3. Nardi DA, Gyurko CC (2013) The global nursing faculty shortage: status and solutions for change. J Nurs Scholarsh 45(3):317-326

4. Hinshaw AS (2001) A continuing challenge: the shortage of educationally prepared nursing faculty. Online J Issues Nurs 6(1):3

5. Burruss NM, Billings DM, Brownrigg V, Skiba DJ, Connors HR (2009) Class size as related to the use of technology, educational practices, and outcomes in web-based nursing courses. J Prof Nurs 25(1):33-41

6. Goldstein IL, Ford JK (2002) Training in organizations: needs assessment, development, and evaluation, 4th edn. Wadsworth, Belmont

7. Juwah C, Macfarlane D, Nicol D, Ross D (2004) Enhancing student learning through effective formative feedback

8. Dornan DT, Littlewood S, Margolis S, Scherpbier A, Spencer J, Ypinazar V (2006) How can experience in clinical and community settings contribute to early medical education? BEME Syst Rev Med Teacher 28(1):3-18

9. Benner P (1984) From novice to expert, Menlo Park

10. Chakravorti N, Le Sage T, Slawson SE, Conway PP, West AA (2013) Design and implementation of an integrated performance monitoring tool for swimming to extract stroke information at real time. IEEE Trans Human Mach Syst 43(2):199-213

11. Burchfield R, Venkatesan S (2010) A framework for golf training using low-cost inertial sensors. In: 2010 International conference on body sensor networks, IEEE, pp 267-272

12. Gray S, Watts S, Debicki D, Hore J (2006) Comparison of kinematics in skilled and unskilled arms of the same recreational baseball players. J Sports Sci 24(11):1183-1194

13. Furuya S, Kinoshita H (2008) Organization of the upper limb movement for piano key-depression differs between expert pianists and novice players. Exp Brain Res 185(4):581-593

14. Solis J, Takanishi A (2008) Enabling autonomous systems to perceptually detect human performance improvements and their applications. In: IEEE International conference on automation science and engineering, pp 259-264

15. Nagata A, Huang Z, Kanai-Pak M, Maeda J, Kitajima Y, Nakamura M, Aida K, Kuwahara N, Ogata T, Ota J (2013) Measurement and evaluation system for self-training system of bed-making activity. Trans Control Mech Syst 2(12):422-431

16. Han J, de With PH, Merien A, Oei G (2012) Intelligent trainee behavior assessment system for medical training employing video analysis. Pattern Recogn Lett 33(4):453-461

17. Huang Z, Nagata A, Kanai-Pak M, Maeda J, Kitajima Y, Nakamura M, Aida K, Kuwahara N, Ogata T, Ota J (2014) Self-help training system for nursing students to learn patient transfer skills. IEEE Trans Learn Technol 7(4):319-332

18. Peteani LA (2004) Enhancing clinical practice and education with high-fidelity human patient simulators. Nurse Educator 29(1):2530

19. Park H-S, Kim J, Damiano DL (2012) Development of a haptic elbow spasticity simulator (hess) for improving accuracy and reliability of clinical assessment of spasticity. IEEE Trans Neural Syst Rehabil Eng 20(3):361-370

20. Takhashi Y, Komeda T, Koyama H, Yamamoto SI, Arimatsu T, Kawakami Y, Inoue K, Ito Y (2011) Development of an upper limb patient simulator for physical therapy exercise. In: 2011 IEEE International conference on rehabilitation robotics, IEEE, pp 1-4

21. Che D, Zhang W (2011) GCUA humanoid robotic hand with tendon mechanisms and its upper limb. Int J Social Robot 3(4):395-404

22. Marshall RL, Smith JS, Gorman PJ, Krummel TM, Haluck RS, Cooney RN (2001) Use of a human patient simulator in the development of resident trauma management skills. J Trauma Acute Care Surg 51(1): 17-21

23. Tanzawa T, Futaki K, Tani C, Hasegawa T, Yamamoto M, Miyazaki T, Maki K (2012) Introduction of a robot patient into dental education. Eur J Dent Educ 16(1):e195-e199
24. Dang T, Annaswamy TM, Srinivasan MA (2001) Development and evaluation of an epidural injection simulator with force feedback for medical training. In: Studies in health technology and informatics, pp 97-102

25. Ogata T, Nagata A, Huang Z, Katayama T, Kanai-Pak M, Maeda J, Kitajima Y, Nakamura M, Aida K, Kuwahara N et al (2016) Mannequin system for the self-training of nurses in the changing of clothes. Kybernetes 45(5):839-852

26. Gerling GJ, Rigsbee S, Childress RM, Martin ML (2009) The design and evaluation of a computerized and physical simulator for training clinical prostate exams. IEEE Trans Syst Man Cybern Part A Syst Humans 39(2):388-403

27. Takashina T, Shimizu M, Katayama H (1997) A new cardiology patient simulator. Cardiology 88(5):408-413

28. Noh Y, Segawa M, Shimomura A, Ishii H, Solis J, Hatake K, Takanishi A (2008) Development of the evaluation system for the airway man agement training system wka-1r. In: 2008 2nd IEEE RAS and EMBS international conference on biomedicalrobotics and biomechatronics, IEEE, pp 574-579

29. Noh Y, Segawa M, Shimomura A, Ishii H, Solis J, Hatake K, Takanishi A (2008) WKA-1R Robot assisted quantitative assessment of airway management. Int J Comput Assisted Radiol Surg 3(6):543

30. Noh Y, Segawa M, Sato K, Wang C, Ishii H, Solis J, Takanishi A, Katsumata A, Iida Y (2011) Development of a robot which can simulate swallowing of food boluses with various properties for the study of rehabilitation of swallowing disorders. In: 2011 IEEE international conference on robotics and automation, IEEE, pp 4676-4681

31. Huang Z, Katayama T, Kanai-Pak M, Maeda J, Kitajima Y, Nakamura M, Aida K, Kuwahara N, Ogata T, Ota J (2015) Design and evaluation of robot patient for nursing skill training in patient transfer. Adv Robot 29(19):1269-1285

32. Huang Z, Lin C, Kanai-Pak M, Maeda J, Kitajima Y, Nakamura M, Kuwahara N, Ogata T, Ota J (2017) Robot patient design to simulate various patients for transfer training. IEEE/ASME Trans Mechatron 22(5):2079-2090

33. Huang Z, Lin C, Kanai-Pak M, Maeda J, Kitajima Y, Nakamura M, Kuwahara N, Ogata T, Ota J (2016) Impact of using a robot patient for nursing skill training in patient transfer. IEEE Trans Learn Technol 10(3):355-366

34. Zhou J, Dai B, Ning X (2013) The assessment of material handling strategies in dealing with sudden loading: influences of foot placement on trunk biomechanics. Ergonomics 56(10):1569-1576

35. Lin C, Kanai-Pak M, Maeda J, Kitajima Y, Nakamura M, Kuwahara N, Ogata T, Ota J (2018) Translational acceleration, rotational speed, and joint angle of patients related to correct/incorrect methods of transfer skills by nurses. Sensors 18(9):2975

36. Garg A, Owen B, Carlson B (1992) An ergonomic evaluation of nursing assistants' job in a nursing home. Ergonomics 35(9):979_ 995

37. Nelson A, Lloyd JD, Menzel N, Gross C (2003) Preventing nursing back injuries: redesigning patient handling tasks. AAOHN J 51(3):126-134

38. Kjellberg K, Lagerstrom M, Hagberg M (2004) Patient safety and comfort during transfers in relation to nurses' work technique. J Adv Nurs 47(3):251-259

39. Jørgensen S, Hein HO, Gyntelberg F (1994) Heavy lifting at work and risk of genital prolapse and herniated lumbar disc in assistant nurses. Occup Med 44(1):47-49

Publisher's Note Springer Nature remains neutral with regard to jurisdictional claims in published maps and institutional affiliations. 